\title{
56. Geçmişten günümüze çok dilli bir bölge: Hong Kong örneği
}

Aylin YILMAZ ŞAŞMAZ ${ }^{1}$

\section{Çile MADEN KALKAN²}

APA: Yılmaz Şaşmaz, A.; Maden Kalkan, Ç. (2021). Geçmişten günümüze çok dilli bir bölge: Hong Kong örneği. RumeliDE Dil ve Edebiyat Araştırmaları Dergisi, (24), 987-1003. DOI: 10.29000/rumelide.996896.

\section{$\ddot{O} \mathbf{z}$}

Hong Kong, 2017 yılı sayım sonuçlarına göre yedi milyonu aşan nüfusu ile Dünya'nın en kalabalık nüfus/yüzölçümü oranına sahip bölgelerinden biri konumundadır. 1842'den sonra yüz elli yıldan fazla bir süre İngilizlerin idaresi altında bulunan bölge, İngilizler tarafindan bir üretim ve ticaret merkezi görevi görmüş ve bu anlamda Doğu’ya açılan bir liman konumunu taşımıştır. İngilizlerin bölgedeki hâkimiyetinin son bulmasından sonra koloni yönetiminden Çin Halk Cumhuriyeti (ÇHC)'ne nispeten sorunsuz bir şekilde teslim edilen bu bölgenin, eski yaşam biçimini sürdürmesi ise devletlerarası yapılan anlaşmalarla sağlanmaya çalışılmıştır. Bu anlamda ve muhtemelen koloni tarihi sebebiyle bölge: İngilizce ile eğitim, ana dilde eğitim ve çok dillilik gibi kavramların en iyi şekilde incelenebileceği; çok dilli eğitim alanında izlenen politika ve gelişmelerin rahatlıkla takip edilebileceği, muazzam genişlikte bir araştırma alanı sunduğu için önemlidir. Araştırmada, bu çok dilli yapının oluşmasını sağlayan olaylar ve nedenler üzerinde durulmuş, bölgede çok dilliliğin geçmişi ve özellikleri mercek altına alınmaya çalışılmıştır. Bu amaç doğrultusunda, tarihsel bağlamı içerisinde Hong Kong'un Kantonca, Çince ve İngilizce ile olan ilişkisi incelenmiş, Hong Kong Sayım ve İstatistik Departmanı'nın özellikle 1931 yılından sonra bölgede kullanılan dillere dair yayımladığı resmi veriler üzerinden nitel araştırma yöntemleri ve betimsel istatistik bakış açısıyla analiz yapılmıştır. Bu doğrultuda bölgede, Hong Kong Eğitim Bürosu tarafından hedef olarak tayin edilen "iki dil okuryazar, üç dil konuşur" bir yapıya doğru gitmek adına gereken adımların atıldığı ve belli bir ivme ile bu hedefe doğru gidildiği sonucuna varılmıştır.

Anahtar kelimeler: Çok dillilik, Hong Kong, Hong Kong’un dil politikası, İngilizce

\section{From the past to the present a multilingual region: the case of Hong Kong}

\begin{abstract}
According to the 2017 census results, Hong Kong has a population more than seven million and is one of the most populous regions in the World. Region came under the British rule after 1842, served as a center of production and trade for more than a hundred and fifty years and has been a port that opened to the East. British rule left behind a region, which was seamlessly handed over to the People's Republic of China. International agreements were made to ensure that after handover the region continued its old way of life. Possibly because of its collonial history, region is one of the best places to study concepts such as English medium of instruction, mother tongue instruction and
\end{abstract}

1 Ars. Gör., Ankara Hacı Bayram Veli Üniversitesi, Edebiyat Fakültesi, Sosyal Bilimler Enstitüsü, Mütercim Tercümanlı Bölümü, Çince Mütercim Tercümanlık ABD (Ankara, Türkiye), aylin.yilmaz@hbv.edu.tr, ORCID ID: 0ooo-0001-78634140 [Araştırma makalesi, Makale kayıt tarihi: 27.08.2021-kabul tarihi: 20.09.2021; DOI: 10.29000/rumelide.996896] Ars. Gör., Ankara Hacı Bayram Veli Üniversitesi, Edebiyat Fakültesi, Sosyal Bilimler Enstitüsü, Mütercim Tercümanlı Bölümü, Çince Mütercim Tercümanlık ABD (Ankara, Türkiye), cile.maden@hbv.edu.tr, ORCID ID: oooo-00o3-47367101

Adres
RumeliDE Dil ve Edebiyat Araştırmaları Dergisi Osmanağa Mahallesi, Mürver Çiçeği Sokak, No:14/8 Kadıköy - İSTANBUL / TÜRKIYE 34714 e-posta: editor@rumelide.com tel: +90 505 7958124, +90 2167730616
Address

RumeliDE Journal of Language and Literature Studies Osmanağa Mahallesi, Mürver Çiçeği Sokak, No:14/8

Kadıköy - ISTANBUL / TURKEY 34714

e-mail: editor@rumelide.com,

phone: +90 5057958124, +90 2167730616 
multilingualism; and also important because it offers a vast area of study about the development of bilingual education and language policies. This study has been focused on the chain of events that led to the emergence and continued existence of Hong Kong's multilingual structure. In line with this aim, relations between Hong Kong and Cantonese, Chinese, and English were studied in historical context, the official data published after 1931 by Hong Kong Census and Statistics Department about language situation in the region have been analyzed from qualitative research and descriptive statistics perspectives. It has been concluded that the region has taken necessary steps to move toward a "bilitarete and trilingual" structure, which is a designated goal of Hong Kong Education Bureau, and has been moving towards that direction with sure steps.

Keywords: Multilingualism, Hong Kong, language policy of Hong Kong, English

\section{Giriş}

Dilbilim, toplumdilbilim, sosyoloji, eğitim ve psikoloji gibi pek çok alanın araştırma konuları arasında kendine yer bulan iki dillilik ve çok dillilik, geçmişten günümüze kapsamsal bir değişim geçirmiştir. Bloomfield'a göre iki dillilik, "ana dil seviyesinde bir hâkimiyet" (Bloomfield, 1935, s.55) gerektirirken, Beziers ve Van Overbeke ise bu kavramı, birbirinden farklı iki dünya, yani iki dil arasında iletişim kurmayı sağlayan, iki sistemin varlı̆̆ olarak tanımlamıştır (Beziers ve Van Overbeke, 1968, s.133). 1980'lerden sonra tanım, tekrar değişerek genişlemiş ve ana dil yanında başka bir dilde temel dil becerilerinden birine minimum düzeyde sahip olmak anlamını da kapsamaya başlamıştır (Macnamara, 1967, s.59). Bu açıdan bakıldığında, çok dillilik ise ikiden fazla dil ya da sistemin, birey/toplum/topluluk tarafından kullanılıyor olması olarak tanımlanabilir. Zaten Mackey iki dilliliği, "iki ya da daha fazla dilin aynı kişi tarafından ardışık kullanımı” (Mackey, 1962, s. 51) olarak tanımlamaktadır3 ki bu tanımdan yola çıkılarak iki dillilik ve çok dillilik kavramları arasındaki farkın, dil sayısında yattığı ifade edilebilir. Bu doğrultuda, araştırma boyunca iki kavram birbiri yerine geçer şekilde kullanılacaktır. ${ }^{4}$

Tarih boyunca pek çok sosyal ve politik olayın dilleri etkilediği, diller üzerindeki değişim ve etkileşimin ise tarihsel olaylar hakkında ipuçları verdiği fikri üzerinden yola çıkıldığında, dili etkileyen etmenlerin bir bütün halinde gözlemlenebileceği, ayrıca iki dillilik, çok dillilik, yabancı dil politikası ve eğitimi gibi konuların mercek altına yatırılarak incelenebileceği en iyi örneklerden biri, yüz elli yıl kadar İngiliz yönetiminde kalmış olan Hong Kong örneğidir.

Çin Halk Cumhuriyeti (ÇHC) tarafından kabul edilmek istenmeyen ve aslen 1842 yllında Qing Hanedanı 5 tarafından imzalanan Nanjing Antlaşması ${ }^{6}$ sonrası, İngiliz yönetimi altına geçen Hong Kong, 1984 yllına kadar İngiliz Hong Kong Koloni Hükümeti tarafından yönetilmiştir. 1841'de İngiliz yerleşimciler bölgeye ilk geldiklerinde bir balıkçı limanı olan Hong Kong, 1945-50'lerde bir ambar limanına, 1960-70'lerde üretim merkezine, 1980'lerde finans merkezine (Poon A. Y., 2010, s. 1),

Aksi belirtilmediği takdirde çalışma boyunca iki dillilik konusunda yapılan tüm açıklamalar doğrudan çok dillilik için de geçerlidir.

İki dillilik, çok dillilik ve özellikleri hakkında daha geniş bilgi için bk. Beardsmore, H. B. (1986). Bilingualism: basic principles (2. Baskl). Bristol: Multilingual Matters; Beardmore, H. B. (2003). Bilingualism: Beyond basic principles. Bristol: Multilingual matters; Hamers, J. F., Blanc, M., \& Blanc, M. H. (2000). Bilinguality and bilingualism. Cambridge: Cambridge University Press.

5 1644-1911 yılları arası Çin topraklarını yöneten hanedandır.

6 Daha çok Nanking Anlaşması adıyla bilinir. 1842 yılında I. Afyon savaşından galip çıkan İngilizler ve Qing Hanedanı arasında imzalanmış olup: savaş tazminatı ödenmesi; bazı limanların İngilizlerin ticaretine açılması, Hong Kong'un İngiliz yönetimine bırakılması gibi kapitülasyonlar benzeri maddeler içerdiği için önemlidir. Konu hakkında daha geniş bilgi için bkz. Kırilen, G. (2014). Çin'de Afyon Savaşları. Ankara: Gece Kitaplığı.; savaş döneminde yabancı dil bilenlerin ülkedeki konumlandırılması hakkında daha geniş bilgi için bkz. Wong, L. W. C. (2007). Translators and interpreters during the Opium War between Britain and China (1839-1842). In Translating and interpreting conflict (pp. 41-57). Brill Rodopi.

Adres Address

RumeliDE Dil ve Edebiyat Araştırmaları Dergisi Osmanağa Mahallesi, Mürver Çiçeği Sokak, No:14/8 Kadıköy - İSTANBUL / TÜRKIYE 34714 e-posta: editor@rumelide.com

RumeliDE Journal of Language and Literature Studies Osmanağa Mahallesi, Mürver Çiçĕ̆i Sokak, No:14/8

Kadıköy - ISTANBUL / TURKEY 34714 tel: +90 $5057958124,+90216773$ o 616

e-mail: editor@rumelide.com,

phone: +90 $5057958124,+902167730616$ 
günümüzde ise uluslararası bir ticaret, finans ve bilgi merkezine dönüşmüştür (Flowerdew \& Miller, 1998, s. 47).

1984'te İngiltere ve ÇHC arasında imzalanan "Ortak Bildirge (Joint Decleration)” 7 hükümleri uyarınca, 1984-97 yılları arası bir el değiştirme süreci yaşamış olan bölge, 1997 yılında Çin hükümetine bağlı bir "Özel İdari Bölge (ÖİB)"” haline gelmiştir. Düzenlenen Ortak Bildirge içerisine, özellikle bölgede yaşayan insanların "kişisel haklarının korunması ve kapitalist yaşam şeklinin devamını" garanti altına alan özel şartlar eklenmiş (Flowerdew \& Miller, 1998, s. 46), bölgenin dışişleri ve savunma konuları haricinde yüksek dereceli bir özerkliğe sahip olması garanti altına alınmıştır (Government of the United Kingdom of Great Britain and Northern Ireland, 1984, para.6).

1990 yllına gelindiğinde ÇHC, Hong Kong'un devir tesliminden sonra uygulamaya konulacak ve hala

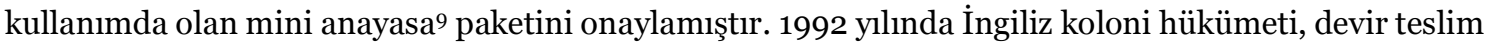
sırasında ve sonrasında yapılacak seçimlerde oy kullanacak tabanı genişletmek adına, bazı reformlara imza atar ki kendisine danışılmamasından rahatsız olan ÇHC, bölge ile yapılmış olan iş mukavelelerini bozmak ve teslim aldıktan sonra yapılan reformları geçersiz kılmakla tehdit etmiştir. Bu durum reformların hemen ardından Hong Kong borsasının çöküşe geçmesine de yol açar. Üzerine iki sene tartışılan reformlar, 1994 yılında koloni hükümeti oy hakkı ile alakalı bölümde daraltmalar yapması sonrası iki taraf tarafından da kabul edilir. 1995 yılında "Yeni Yasama Konseyi” seçimleri ve 1997'deki devir teslimin ardından, sonraki sene ilk seçimler yapılmıştır. Bu süreçte en önemli başlıklardan biri olan anayasanın kabulü (1990), 1997 yllında yürürlüğe girdikten sonra, Hong Kong'daki diller için de bir koruyuculuk sağlamıştır. Anayasa içerisinde, bölgenin resmi dilleri ile ilgili ve bölgede varlığını sürdüren azınlık ve halkların dilsel yapısının devamına yönelik de şartlar bulunmaktadır. Mesela: Madde 5, "tüm etnik grupların kendi konuşma ve yazı dillerini kullanma ve geliştirme özgürlüğünü"; Madde 9, "Çincenin yanında, İngilizcenin de yasama, yürütme ve yargı organlarında resmi dil olarak kullanılabileceğini”; Madde 121, etnik grupların yaşadığı bölgelerde yetkili mercilerin, "bölge genelinde kullanılan dil yahut dillerin konuşma ve yazısının kullanmasını"; Madde 136, eğitim dili de dâhil olmak üzere, eğitim sistemi ile alakalı her konuda HKÖİB'si hükümetinin yetkili olduğunu; Madde 139, "etnik grupların kendi konuşma ve yazı dillerini yargı işlemlerinde kullanabilmesini" ve "etnik grupların toplu yaşadığı bölgelerde dava duruşmalarının yerel dil üzerinden yapılmasını” (ÇHC, 2021, s. 8, 47, 51, 59, 99) teminat altına alarak bölgedeki çok dilliliğin $1997^{\prime}$ den sonrası için de devamını teminat altına almış görünmektedir.

Bölgenin ekonomik yapısının 1950'lerden itibaren gelişmesi ile beraber, dünyanın her bölgesinde olduğu gibi, insan gücüne duyulan ihtiyaç burada da artmış, Hong Kong’un özellikle II. Dünya savaşı ve sonrasında dış ticaret ile ilişkilenen varlığ (Li D. , 2017, s. 73), bölgede iş bulabilmek için İngilizce ve Mandarin Çince ${ }^{10}$ öğrenme zorunluluğunu da beraberinde getirmiştir. Bu doğrultuda, koloni tarihi

Bildirge içeriği ile ilgili daha geniş bilgi için bkz. ( The Government of the People's Republic of China and The Government of the United Kingdom of Great Britain and Northern Ireland, 1984); People's Republic of China-United Kingdom: Agreement on The Future of Hong Kong. (1984). International Legal Materials, 23(6), 1366-1387.

$8 \quad$ Yurt dışı kaynaklarında ve Türkiye'de de yayımlanan araştırmalarda genellikle, "Special Administration Region"un kısaltması "SAR" olarak kullanılmasına rağmen bu araştırma boyunca, özel isim ve ifadelerin Türkçe kısaltmalarının kullanılması tercih edilmiștir. ÖİB hükümeti ve ÇHC arasındaki geçmişten 9o'lara gelen ilişkinin seyri hakkında bkz. Cheng, Joseph. (1988). "The Constitutional Relationship Between the Central Government and the Future Hong Kong Special Administrative Region Government." 20 Case W. Res. J. Int'l L. s.65-79.

9 Anayasa yabancı kaynaklarda "Basic Law of Hong Kong” ismiyle bilinmektedir. Anayasa'nın içeriği ve güncel hali için bk. https://www.basiclaw.gov.hk/filemanager/content/en/files/basiclawtext/basiclaw_full_text.pdf

ÇHC'nin resmi dili olan Modern Standart Çince, konuşmada Pekin diyalektini temel alır. Bu diyalekt, Kuzey yahut Mandarin diyalekti olarak da bilinmektedir. Bu nedenle araştırmanın bundan sonraki bölümlerinde "Mandarin, Mandarin Çince" ifadeleri ÇHC resmi konuşma dilini belirtmek için kullanılacaktır. Konuşma dili olarak bakıldı̆̆ında Hong Kong'da kullanılan Kantoncadan neredeyse tamamen farklı bir dil sayılabilecek Mandarin Çince’nin yazı dili, basitleştirilmiş Çince

Adres Address

RumeliDE Dil ve Edebiyat Araştırmaları Dergisi Osmanağa Mahallesi, Mürver Çiçeği Sokak, No:14/8 Kadıköy - ISTANBUL / TURKIYE 34714 e-posta: editor@rumelide.com

RumeliDE Journal of Language and Literature Studies Osmanağa Mahallesi, Mürver Çiçeği Sokak, No:14/8

Kadıköy - ISTANBUL / TURKEY 34714 tel: +90 $5057958124,+902167730616$

e-mail: editor@rumelide.com,

phone: +90 $5057958124,+902167730616$ 
nedeniyle Asya üzerinde pek çok politik ve ticari olayın merkezi olarak yükselen Hong Kong'un dilsel yapısını incelenmeye değer kılan nedenlerin başında, bölgenin geçmişi ve günümüze uzanan süreçte çok dilli yapının korunması adına atılan adımların, araştırma alanını genişletmesi gelmektedir. 1990'ların sonuna kadar devam eden sömürge statüsü ise bölgenin önce iki dilli ardından çok dilli bir yapıya kavuşmasının en önemli sebebi olarak gösterilebilir.

Genellikle başka bir ülkenin hâkimiyeti altında kalmış iki dilli toplumlarda, diller kullanım yerine göre: 1) Hükümet, eğitim, hukuk ve iş hayatı gibi resmî (yüksek), yani statü ve hiyerarşi sembolü olan alanlarda; 2) Ev, aile, arkadaş ortamı gibi gayri resmî (düşük), yani dayanışma ve eşitlik sembolü olan alanlarda kullanılanlar, şeklinde sınıflandırılabilir (O'Halloran, 2000, s. 145; Pennington \& Balla, 1998, s. 243). ${ }^{11}$ Sinıflandırmaya göre, Hong Kong bölgesinde koloni hükümeti boyunca İngilizce’nin, "yüksek" statülü dil, yani resmi dil olarak, ana dil olan Kantonca'nın ise "düşük" statülü, yani gayri resmî dil olarak işlev gördüğ̈̈;12 günümüzde ise 1997 yılından sonra Mandarin Çince'nin de devreye girmesi ile artık resmi işlerde dahi üç dilin birbiri içine geçmiş şekilde kullanıldığı, bölgede birden çok dile hâkim insanların, istemsiz olarak, konuşurken diller arası geçiş yaptığı (code switching) (Appel \& Muysken, 1987, s. 117-118) ${ }^{13}$ ifade edilebilir. Bu da bölgenin, diglossik ${ }^{14}$ yani iki değişken dilli bir toplumdan, karma kodların15 hızlı bir biçimde çoğaldığı "yüksek" Çince ve İngilizcenin, hatta "düşük" Kantoncanın bile birbiri yerine sürekli kullanıldığı, çok dilli bir topluma doğru gelişmekte olmasına vurgu yapar (O'Halloran, 2000, s. 145). Bu durumun ortaya çıkması: koloni hükümetinin idaresi sebebiyle bölgede resmi dil olarak İngilizcenin hala kullanımda olması; ÇHC'ne nispeten "sorunsuz ve kolay" 16 geçen devir teslim sonrası ana dilde eğitime geçilmesi yani yerel ortaokulların çoğunun Kantonca eğitime geçmiş olması; okullarda Mandarin Çince'nin zorunlu ders olarak okutulmaya başlanması gibi dil politikalarına bağlanabilir (Lai, 2013, s. 311).

olarak da bilinir. Hong Kong'da ise resmi yazı dili olarak hala klasik Çince kullanılmaya devam edilmektedir. Mandarin Çince'nin karakteristik özelliklerini daha net anlamak için bkz. Ho, D. A. (2003). The characteristics of Mandarin dialects. The Sino-Tibetan languages, 126-130.

${ }_{11}$ Bu sınıflandırmayı diglosik dil yapısının açıklanmasında ilk kullanan araştırma için bk. Ferguson, C. A. (1959). Diglossia. word, 15(2), 325-340. Ferguson, diglosik yapı ile alakalı, bir konuşma toplumu içinde bir dilbilimsel sistemin: "yüksek",yani resmi; düşük, yani halk dili ya da popüler olmak üzere, iki türü ihtiva ettiğini anlatır.

12 Hong Kong'da, "yüksek" ve "düşük" statü sahibi diller hakkında bilgi için bk. (Pennington \& Balla, 1998, s. 242-245).

13 Burada aslen kullanılan dillerin işlevlerine vurgu yapılmaktadır. Konu hakkında detaylı bilgi için bk. Pennington, M. C. (1998). Language in Hong Kong at century's end (Vol. 1). Hong Kong: Hong Kong University Press.

14 Diglossia kelimesinden gelen bu kavram farklı dillerin bir toplumda farklı işlevler için kullanılmasını açıklayan bir terimdir.

$15 \quad$ Karma kod yahut karma dil, en yalın ifade ile iki dilli bir toplumda, dillerin birbiri ile eşit tutulmaya başlanmasıyla ortaya çıkan melez dile verilen isimdir. Konu hakkında bilgi için bk. Karaağaç, G. (2011). "Bireysel İki Dillilik ve Toplumsal İki Dillilik", Türk Dili Dil ve Edebiyat Dergisi, (717), s. 222-228.

1984-97 arası koloni hükümetinin bölgede yarattı̆̆ değişikliklere bir nevi sahne olmuş, Hong Kong ekonomik ve sosyal bağlamda daha evvel hiçbir sömürgede rastlanmayan kadar iyi bir durumda, Çin hükümetine devredilmiștir. Hong Kong'daki dil durumunun ve diğer İngiliz sömürge bölgelerine oranla Çin hükümeti yönetimine geri dönerken yaşanan nispeten kolay geçişin belli başlı sebepleri bulunmaktadır. Flowerdew ve Miller (1998) bu sebeplerin en önemlilerini aşağıdaki gibi sıralar: 1) Hong Kong'un nüfusunun büyük çoğunluğunun köklerinin aslında hala ÇHC'de bulunması. Nüfusun çoğu, buraya Çin'de yaşanan sorunlardan ve kötü yaşam koşullarından kaçmak adına sığınan göçmenlerden oluşmaktadır. Hong Kong'luların koloni hükümetine karşı bu sebepten ötürü bir bağımsızlık savaşına girişmedikleri de düsünülebilir; 2) 1984-97 arası uzun süren el değiștirme süreci, hükümetlerin devir teslimden sonrası için kendini ve bölgeyi hazırlamaları adına yeterli süreye sahip olmasını sağlamıştır; 3) Hong Kong'un 1960-1970'lerde ${ }^{16}$ kendi kimliğini yaratma çabaları sonuç vermiş ve ÇHC ile yapılan devir anlaşmasında yeniden inşa edilen sosyal yapı izdüşümünde, toplumun yaşam standartları ve biçiminin korunmasına dair şartlar da anlaşma metnine eklenmiş̧ir; 4) Diğer koloni teslimi durumlarında yeni kurulan hükümet radikal politik görüşlere sahipken, anlaşma şartları uyarınca Çin hükümeti tarafindan kurulan ilk Hong Kong Özel İdari Bölge Yönetim Hükümeti, bölge insanları arasından ve kapitalist zümre içinden itina ile seçilmiş işadamlarından oluşturulmuştur; 5) Hong Kong, özellikle 1970'lerin son döneminden itibaren sosyal ve ekonomik yapısını oturtmasıyla beraber, diğer sömürge bölgelerden maddi anlamda çok daha zengin durumdadır. Bu dönemden sonra güçlü bir ekonomiye sahip olan Hong Kong, hala dünyadaki kişi başına düsen milli hasılanın en yüksek olduğu bölgelerden birisi konumunu korumaktadır; 6) Hong Kong’un diğer kolonilerin bağımsızlık mücadelelerini ve sonuçlarını görmüş ve onlardan feyz almış olması gösterilebilir (Flowerdew \& Miller, 1998, s. 53-55).

Adres $\mid$ Address

RumeliDE Dil ve Edebiyat Araşturmaları Dergisi Osmanağa Mahallesi, Mürver Çiçeği Sokak, No:14/8 Kadıköy - ISTANBUL / TÜRKIYE 34714 e-posta: editor@rumelide.com tel: +90 $5057958124,+902167730616$

RumeliDE Journal of Language and Literature Studies

Osmanağa Mahallesi, Mürver Çiçeği Sokak, No:14/8

Kadıköy - ISTANBUL / TURKEY 34714

e-mail: editor@rumelide.com,

phone: +90 505 7958124, +90 2167730616 
Nüfusunun \%9o'dan fazlası etnik Çinli olan Hong Kong'un iki dilli yapısı incelendiğinde, halkının İngilizceyi daha çok resmi kurumlar ve iş alanlarında kullandığı söylenebilir. Bu doğrultuda, bölgede İngilizce öğrenimindeki temel amacın "daha kolay ve daha çok kazanç sağlanabilecek bir işe sahip olma şansını arttırmak” (Yip, Tsang, \& Cheung, 2003, s. 296) olduğu sonucuna varılabilmektedir ki bölgede kullanılan diller, diller arası hiyerarşi ve benzeri konulara daha hâkim olabilmek için yakın tarih boyunca gelişmekte ve değişmekte olan çok dilli yapının incelenmesi faydalı olacaktır.

Bu anlamda, özellikle 1997'den beri, bölgede kullanılan üç dilin eğitimde oynaması gereken rol üzerine düşünmüş ve şehrin ekonomik ve politik altyapısına uygun, aynı zamanda halkın kültürel ve sosyal yapısını bozmayacak bir dengenin kurulabilmesi adına yapılması gerekenleri tespit etmek için bölgenin İngiliz idaresinde kaldığı son yirmi yılda yapılan çok sayıda araştırma üzerinde incelemeler yapmış olan Hong Kong hükümetinin rapor ve istatistiksel verilerinin kullanılması daha net sonuçlar verecektir. $\mathrm{Bu}$ doğrultuda, bahsi geçen incelemelerin sonuçlarını yayımlayan: Hong Kong İdari Bölgesi Eğitim Bürosu (2009; 2010), Eğitim Komisyonu (2005) ve Sayım ve İstatistik Departmanı (2002; 2017a; 2017b)'nın rapor ve sayım sonuçları resmi web sitelerinden alınarak araştırmanın temel veri kaynakları olarak kullanılacaktır. ${ }^{17}$ Bölgenin genel dilsel yapısı ve tarihçesi ile alakalı; Bacon-Shone (2008), Chan (2014), Evans (2002; 2013), Evans ve Morrison (2017), O’halloran (2000), Poon (2010; 2013), Poon ve Lau (2016) gibi özellikle son yirmi yılda yapılan önemli çalışmaların da konunun arka planının daha net açlklanabilmesi için incelenmesi gereklidir. Pennington (1998), Poon ve Lau (2016), Tsang (2008)'nn öğrenci ve öğretmenler arasında eğitim dili ile alakalı anket ve araştırmalarının sonuçları ise bölgenin eğitim dili ve politikasının izlediği seyrin anlaşılması adına önemli görülmektedir.

\section{Geçmişten günümüze Hong Kong’un iki dilli yapısının gelişimi}

Hong Kong'un İngiliz yönetimi altına girmesinden itibaren günümüze kadar geçen süre, bölgede konuşulan ve kullanılan diller açısından bazı önemli dönemlere ayrılarak incelenebilir. Bunların ilki, Hong Kong’un İngiliz yönetimine girdiği ve İngiliz güçlerinin bölgede çok güçlü olduğu 19.yy sonlarından II. Dünya Savaşının hemen bitimine kadar olan dönemdir. Bu dönemde bölgede hâkim dil olan Kantonca, nüfusun çok büyük bir bölümü tarafından konuşulmaktadır. Yerel nüfusun elit tabakasının yanında bazı misyoner ve devlet okulu mezunları da Kantonca ve İngilizce konuşabilmektedir, ancak saylları azdır. Düşük orana rağmen, 1974 yılından Hong Kong’un Çin hükümeti yönetimi altına gireceği 1997 yllına kadar, İngilizce hem resmi hükümet dili hem de hukuki dil olarak işlev görmüştür (Bacon-Shone \& Bolton, 2008, s. 26; Flowerdew \& Miller, 1998, s. 46-47).

Li (2017)'ye göre ise süreç biraz farklıdır; en önemli dönem, iki dünya savaşının arasında başlar. Bir liman şehri olan Hong Kong bu dönemde, gelirinin büyük çoğunluğunu ambar ticaretinden elde etmektedir. Bu durum 1950'lere kadar devam eder. Sonraki otuz yılda ise bölge "Doğu'nun İncisi" lakabını taşıyan bir üretim bölgesine dönüştürülür (Li D. , 2017, s. 73).

Bacon-Shone ve Bolton’a göre, ikinci önemli dönem 1970’lerden sonra başlamış ve bölge 1997 yllında Çin hükümetine teslim edilene kadar devam etmiştir. Bu döneme dair Bacon-Shone ve Bolton şunları ifade eder:

Koloni devrinin sonlarına doğru özellikle 1970’lerin sonrasında “modern” Hong Kong toplumunu yaratabilmek adına, İngilizcenin yayılımında bir artış olmuştur. Bu dönemde toplumdaki orta gelirli

17 Bahsi geçen resmi kaynaklar, en son 2017 yılında veri yayınlamışlardır. Bu nedenle yapılan araştırma sonuçları da bu zamana kadar olan resmi veriler üzerinden çalışılmıştır. Yeni resmi verilerin 2022 yılı ortalarında yayımlanması beklenmektedir.

RumeliDE Dil ve Edebiyat Araştırmaları Dergisi Osmanağa Mahallesi, Mürver Çiçeği Sokak, No:14/8 Kadıköy - ISTANBUL / TÜRKIYE 34714 e-posta: editor@rumelide.com tel: +90 $5057958124,+90216773$ o 616
Address

RumeliDE Journal of Language and Literature Studies

Osmanağa Mahallesi, Mürver Çiçeği Sokak, No:14/8

Kadıköy - ISTANBUL / TURKEY 34714

e-mail: editor@rumelide.com,

phone: +90 $5057958124,+902167730616$ 
insan sayısı artmış ve bu kesimin etkisi güçlenmiştir. Bunun nedeni olarak 1966-67 arası ortaya çıkan sosyal huzursuzluk ve ayaklanmalar gösterilmiş, bu durum 1970’lerin koloni hükümetini sosyal sorunlar ile ilgili reformist bir politika izlemeye itmiş ve sonucunda halka çok geniş bir sosyal hizmet ağı sunulmasını sağlamıştır. Bu ağın içinde sağlık, ulaşım, konaklama ve eğitim gibi orta ve dar gelirli kesimin ihtiyaçlarına karşılık veren pek çok sosyal hizmet bulunmaktadır. 1870'lerde İngiltere'de yürürlüğe giren İngiliz Eğitim Hareketi (herkes için ilkokul eğitimi sağlama) 1974’de, 1944'teki İngiliz Eğitim Hareketi (herkes için ortaokul eğitimi sağlama) ise 1978 yılında Hong Kong'da uygulamaya konulmuştur (Bacon-Shone \& Bolton, 2008, s. 27).

Eğitim alanında yürürlüğe sokulan değişiklikler aslında çıkan ayaklanmaların ${ }^{18}$ önemli yansımalarından biri olarak karşımıza çıkmaktadır. Bacon-Shone ve Bolton (2008, s.28) ayaklanmaların sonuçlarından şu ifadeler ile söz eder:

Bu sonuçlar 1974'de Çincenin hükümet ve resmi kurumların ikinci dili olarak resmen kabul edilmesi olarak karşımıza çıkar. Yani Hong Kong hükümeti 1974 yılından itibaren resmen iki dilli bir yönetime kavuşmuş, bunun doğal bir sonucu olarak da bölgede iki dillilik oranlarında ciddi bir artış gözlenmeye başlanmıştır. Aileler çocuklarına İngilizce öğretilmesini talep etmeye başlamış ve bunun bir sonucu olarak da 1970'lerden sonra okul kitapları İngilizceye dönmüş, gerçekte ismen de olsa ortaokul eğitimi İngilizce verilmeye başlanmıştır (Bacon-Shone \& Bolton, 2008, s. 28). ${ }^{19}$

Hong Kong'un 1966-1967'deki ayaklanmalar ile ortaya çıan ve 70'lerde hükümetin sosyal reformlar ile cevap verdiği kimlik ve hak arayışının en önemli sonuçlarından biri; "koloni hükümetinin 1974'de İngilizce ile beraber Çinceyi de bölgenin resmi dili” (Flowerdew \& Miller, 1998, s. 53) olarak kabul etmesidir. ${ }^{20} \mathrm{Bu}$ adım, Kantonca ve İngilizce arasındaki keskin işlevsel sınırın değişmesi yönünde yapılan ilk resmi adım olmuştur.

1980'lerden itibaren Hong Kong'un temel gelir kaynağı olan imalat sektörü yerini "bilgi-temelli ekonominin göstergesi olan bankacılık, yatırım ve finans, ithalat-ihracat, telekomünikasyon, taşımacılık ve lojistik, turizm, otel ve restoran işletmeciliği, sigorta, emlak, perakende ticaret gibi sektörlere bırakır" (Li D. , 2017, s. 73). Bu ekonomik değişim, bölgenin özellikle İngilizce ile olan ilişkisini etkilemiş, 198o ve sonrasında Kantonca, Mandarin Çince ve İngilizce konuşan, aynı zamanda Çince ve İngilizce okuyup yazabilen beyaz yakalı kesime olan ihtiyacın çoğalmasına yol açmıştır denilebilir. Aynı dönemlerde Deng Xiaoping ${ }^{21}$ liderliğinde "Çin karakteristik özelliklerine sahip bir sosyalizm" (Flowerdew \& Miller, 1998, s. 54) anlayışını benimseyen Çin hükümeti, yurt dışına açılmaya ve ticari anlamda dünya devleri arasında isim yapmaya da başlar. ÇHC'de yaşanan bu değişim, Mandarin Çincenin gitgide daha fazla insan tarafından öğrenilmesine yol açarken 1980'ler ve sonrasında İngilizcenin de Çin hükümeti için daha çok değer kazanması kaçınılmaz olur. Doğal olarak bu değer kazanımı, 1997 yılında Çin hükümeti

18 1966-1967'de çeşitli iş sektörlerinde ucuza çalıştırılan işçiler tarafindan toplu iş ihtilafı yüzünden başlayan kargaşa ve grevler, Çin Komünist Partisi yandaşlarının polisle çatışmalar yaşaması ve pek çok insanın ölümüyle sonuçlanmıştır. Sol kanat savunucuları, sağ kanada ve koloni hükümetini destekleyenlere saldırılar düzenlemiş, durum hızla grevden iç kargaşaya doğru sürüklenmiştir. Çin'de devam etmekte olan Kültür Devrimi'nin de etkisi ile gelişmiş olan bu grev ve anlaşmazlık ortamı gitgide büyümüş, hükümet karşıtı gösterilere öğrenciler de dâhil olmuş, ardı ardına yaşanan bombalamalarla devam eden olaylar toplamda 18 ay sürmüştür. İç huzursuzluğun sonlanmasından sonra hükümet aktif olarak endüstriyel planlamaya dâhil olmuş, yaşananların en önemli yansıması ise ardından gelen sosyal reformlarla kendini göstermiştir. 1970'lerde yapılan reformlar, Hong Kong halkının yaşamını yeniden şekillendirerek bölgeyi, yüksek teknoloji endüstrisi üzerine kurulu, refah seviyesi yüksek bir ekonomiye dönüștürerek bölgenin dört Asya Kaplanı'ndan biri haline gelmesini sağlamıștır. Eğitim ve dil politikası ile alakalı, sosyal reformlar şu şekilde sıralanabilir: 1. 9 yıllık zorunlu eğitim; 2. Ücretsiz ilköğretim ve ilkokullara devlet desteği ki bu destek 1978'den sonra liselere de verilmeye başlanır. 3. Kantoncanın bölgede İngilizce ile beraber resmi dil olarak kullanılmaya başlanması. Dönem ve reformlar hakkında bk. Bickers, R., \& Yep, R. (2009). May days in Hong Kong: Riot and emergency in 1967 (Vol. 1). Hong Kong University Press.; Cheung, G. K. W. (2017). How the 1967 riots changed Hong Kong's political landscape, with the repercussions still felt today. Civil Unrest and Governance in Hong Kong içinde (s. 63-75). London: Routledge. Burada Çinceden kasit Kantoncadır.

Burada "Çince" ile ifade edilmek istenen konuşma dili olarak Kantonca ve yazı dili olarak klasik Çincedir. 1978-1992 yılları Çin devlet başkanlı̆̆ı görevinde bulunmuş, politikacı, ve reformcu devlet adamıdır.

Adres $\mid$ Address

RumeliDE Dil ve Edebiyat Araştırmaları Dergisi Osmanağa Mahallesi, Mürver Çiçeği Sokak, No:14/8 Kadıköy - İSTANBUL / TÜRKIYE 34714 e-posta: editor@rumelide.com tel: +90 $5057958124,+902167730616$

RumeliDE Journal of Language and Literature Studies

Osmanağa Mahallesi, Mürver Çiçeği Sokak, No:14/8

Kadıköy - ISTANBUL / TURKEY 34714

e-mail: editor@rumelide.com,

phone: +90 505 7958124, +90 2167730616 
yönetimine iade edilen Hong Kong bölgesinin, hem dilsel (İngilizce bilen insan gücü) anlamda hem de Çin hükümetinin dışa açılım politikası bağlamında önemini korumasını ve hatta arttırmasını sağlar.

Bu dönüşümde büyük etkiye sahip diğer bir önemli olay ise 1984 yllında İngiltere ve Çin hükumeti arasında Hong Kong'un akıbetine dair imzalanan ve koloni hükümetinin 1997 yllında bölgeyi ÇHC idaresi altına geri vermesini öngören anlaşmadır (Li S. M., 1990, s. 84). Bu anlaşmanın sonrasında İngiliz Koloni Hükümeti devir teslimden evvel, bölgedeki siyasi ve sosyal gücünü sağlamlaştırmak adına Hong Kong'da idari bazı değişiklikler yapmaya karar verir.

Bu değişikliklerin içinde önemli başlıklardan biri, koloni hükümeti tarafından bölgede açılan altı yeni üniversitedir. Bu üniversiteler sayesinde bölgede İngilizce eğitim veren üniversite sayısını arttıran koloni hükümeti, İngilizcenin bölgenin vazgeçilmezlerinden biri olmasını sağlamaya çalışmış ve bunda başarılı olmuştur denilebilir. Hong Kong'da 2010 yılına kadar kurulmuş olan sekiz üniversitenin altısı "İngilizce eğitim dili (EDİ)”22 olan okullardır. Bu üniversitelerin açılmasıyla beraber İngilizce, çocuklarını üniversiteye gönderebilmek adına orta ve dar gelirli aileler tarafından da öğrenilmesi zorunlu görülen bir dil haline gelmiştir. Çünkü ortaokul ve lise çağında EDİ olan okullarda öğrenim gören çocukların doğal olarak bu üniversitelere daha kolay gireceği, orada aldıkları eğitimden daha çok fayda sağlayacakları ve üniversite sonrasında daha iyi iş imkânlarına (Evans, 2013, s. 303-304) sahip olacakları düşünülmektedir. Aynı zamanda Hong Kong'lu çoğu aile İngilizceyi ticaretin dili olarak gördüğü için bu dili sosyal yükselmenin zaruri şartlarından biri olarak nitelendirmektedir (Chan, 2014, s. 461). Yani koloni hükümetinin yönetimi devretmesinden sonra da İngilizce bölgede var olan statüsünden bir şey kaybetmemiş, hatta açllan üniversiteler ve ticaretin gelişimi sayesinde yerini sağlamlaştırmıştır.

Bu sebepten, İngilizce eğitim veren üniversitelerin açılmasının, çocuklarının geleceği için endişelenen ailelerin, daha iyi İngilizce eğitim verdiği iddia edilen ortaokul ve liselere yönelmesine sebep olduğu söylenebilir. Bu durumun doğal bir sonucu da bölgede bulunan orta ve lise eğitimi veren okulların, konu üzerinde yetkin olup olmadıklarına bakmaksızın, eğitim dili olarak İngilizceyi tercih etmesidir. Velilerin ve okulların ne yazık ki burada göz ardı ettiği önemli bir diğer konu, ilkokulda "eğitim dili Çince (EDÇ)" 23 veren okullardan gelme çocukların EDİ ortaokul ve liselerde eğitim alabilecek İngilizce yeterliliğe sahip olmamalarıdır (Evans, 2013, s. 304).

Koloni hükümetinin geçiş döneminde, kurulan bu üniversitelerin yanı sıra orta ve lise düzeyinde İngilizce ile eğitim verilmesi için okullara son derece fazla kaynak aktardığı bilinmektedir. Zaten İngiliz Koloni Hükümetinin son valisi 1996 ylında yaptığı konuşmasında "İngilizceyi, İngiliz hükümetinin önceki kolonisine bıraktığı en önemli miras” (Flowerdew \& Miller, 1998, s. 56) olarak tanımlamıştır. Ancak fon aktarılan bu okullarda sık karşılaşılan sorunlardan bir diğeri ise İngilizce kullanarak eğitim verme yeterliliğine sahip öğretmen sayısının yetersiz kalmasıdır. Yani bu dönemde hem öğrenciler hem de öğretmenler yeterli İngilizce seviyesine sahip değillerdir ve bu nedenle aslında sinıflarda yarı Kantonca yarı İngilizce karma bir eğitim verilmektedir (Education Commission , 2005, s. 6).

Üçüncü en önemli dönem ise 1997 yllında Hong Kong'un ÇHC yönetimi altına devredilmesinden günümüze uzanan dönemdir denilebilir. Dönemin en önemli özelliği Çin hükümetinin "ana dilde eğitim" üzerine uygulamaya koyduğu sıkı politika ile kendini gösterir. Bu politikanın ortaokul düzeyinde

\footnotetext{
${ }_{22}$ Kısaltma, genellikle yabancı ve yerli kaynaklarda, "English Medium of Instruction"nun kısaltması EMI şeklinde kullanılmıştır. Ancak araştırmada kısaltmalarda Türkçe kullanılması uygun görülmüştür.

${ }_{23}$ Chinese Medium of Instruction (CMI) içerisinde, Çince derken kastedilen aslında Kantonca konuşma ve Klasik Çince yazı dilidir.

Adres | Address

RumeliDE Dil ve Edebiyat Araşttrmaları Dergisi $\quad$ RumeliDE Journal of Language and Literature Studies

Osmanağa Mahallesi, Mürver Çiçeği Sokak, No:14/8 $\quad$ Osmanağa Mahallesi, Mürver Çiçeği Sokak, No:14/8

Kadıköy - İSTANBUL / TÜRKIYE 34714 Kadıköy - ISTANBUL / TURKEY 34714

e-posta: editor@rumelide.com $\quad$ e-mail: editor@rumelide.com,

tel: +90 $5057958124,+902167730616$ phone: +90 505 7958124, +90 2167730616
} 
uygulamaya koyulmasının temel nedeni, Hong Kong'luların ulusal kimlik anlayışı ve milliyetçi duygularını güçlendirmek, olarak algılanmıştır (Chan, 2014, s. 461; Poon A. , 2013, s. 36). Hong Kong Özel İdare Bölgesi (HKÖİB) 24 bu dönemde ana dilde eğitimin yanı sıra hükümet tarafından açılmış ya da maddi olarak desteklenmekte olan tüm okullarda Mandarin Çince konuşma derslerinin de zorunlu olarak konulmasını talep etmiş (Wang \& Kirkpatrick, 2015, s. 7), bu durum da Hong Kong'un konuşma dilinde üç, yazı dilinde ise iki dilli bir bölge olma yolunda hızla ilerlemesini sağlamıştır. Hong Kong Özel İdari Bölgesi kanunlarına göre, özellikle devlet dairelerinde ve hukuk dili olarak, Kantoncanın yanısıra İngilizce de resmi dil statüsünde kullanılmaktadır.

1950-60 arası İngilizce genel olarak sadece üst düzey hükümet çalışanları, hukukçular, eğitimciler ve işadamları gibi ufak bir grup için bir gereklilik olarak kendini hissettirse de özellikle 1980'lerin ortalarına doğru bu durum ekonominin bilgi temelli yönlere kayması ve ÇHC sınırlarında yaşanan politika değişiklikleri sebebiyle değişmiştir.

1960-80 arası ortaokulda EDİ kullanarak eğitim alan öğrenci sayısında hızlı bir artış gözlenmiş bu durum özellikle 8o'lerde kendini iyice hissettirmiştir. 1985 yllına gelindiğinde ilkokul düzeyinde yaklaşık 491.00o kişi EDÇ eğitim görürken, ortaokul düzeyinde bu sayı 37.00o kişiye kadar düşmüş ve EDİ ortaokullarındaki öğrenci sayısı 1960 yılında 44.00o'ken 1985 yılında 358.00o'e kadar çıkmıştır (Evans, 2002, s. 100-01).

Bu durumda İngiliz koloni hükümetinin payı da yadsınamaz boyuttadır. Aslında hükümet ana dilde eğitimi konusunu ihmal ettiği için çok da eleştiri toplamasına rağmen (Lin \& Man, 2009, s. 74), yukarıdaki rakamlara bakılacak olursa aslında 1974 sonrası başlattığı ana dilde "ilköğretim" politikasında çok başarılı olduğu söylenebilir (Evans, 2013, s. 304).Özellikle bu dönemde, İngiliz hükümetinin Qing Hanedanı ile düzenlediği ve Hong Kong idaresinin, 99 ylllı̆ğına İngiliz Koloni Hükümeti yönetimine bırakılmasını içeren anlaşmanın süresi dolmaya yaklaşmış ve 1984'te kontratın ÇHC Hükümeti tarafından yenilenmeyeceği açıklanmıştır. Bunun yarattığı ekonomik, sosyal ve politik etkilerden bazıları da dile ve dil eğitimine olan yansımaları sebebiyle ilgi çekicidir.

\section{7'den sonra Hong Kong'un dil politikası ve çok dilli yapıya etkisi}

Özerk bölge statüsünü aldıktan hemen sonra bölgede hangi dillerin kullanılacağı, hangi dillerle eğitim verileceği ve bu eğitimin ne koşullar altında, kim tarafından verileceği konuları Hong Kong yönetiminin önem göstermek zorunda kaldığı konular arasına girmiştir. Bu doğrultuda, bölgede hangi dillerin öğretileceğine tarihten günümüze koloni hükümeti ve HKÖİB hükümetinin karar verdiği ifade edilebilir. Çocuklarının geleceğini garanti altına almak için çaba sarf eden ailelerin yarattığı baskının ve iş sektörlerinin ihtiyaçlarının da bu kararlarda etkili olduğunu söylemek yanlış olmaz. Miguel PérezMilans, Dil ve Eğitim Ansiklopedisi'nde yayımlanan araştırmasında bölgede kullanılan en önemli iki dil yani İngilizce ve Kantoncanın yeri ve önemine dair şu açıklamaları yapar:

19.yy'da Avrupa'da burjuvazinin yükselişe geçmesi ve birleşik ulusal pazarlarda yürüttüğü ekonomik faaliyetler ile beraber bölgede devamlı kullanılan Çince ve İngilizce, buranın iki dilli bir çerçeveye kavuşmasına yol açmıştı. Bir yandan İngilizce Yüksek Öğretim, elit iş imkânları ve sosyal ağlara erişim ile ilişkilendirilirken, diğer bir yandan sadece Çince biliyor olmak az gelirli aileler ile ilişkilendirilmişti. Yani tarihsel açıdan İngilizce Hong Kong'un sosyoekonomik pazarında baştan beri "sembolik bir kapital" (Bourdieu, 1991) olarak inşa edilmişti ki bu sınıf-temelli hiyerarşik yapıların

\footnotetext{
24 “Hong Kong Özel İdari Bölge”nin yabancı kaynaklarca kullanılan kısaltması HKSAR’dır.

Adres $\mid$ Address

RumeliDE Dil ve Edebiyat Araşttrmaları Dergisi $\quad$ RumeliDE Journal of Language and Literature Studies Osmană̆a Mahallesi, Mürver Ciçeği Sokak, No:14/8 $\quad$ Osmanağa Mahallesi, Mürver Çiçeği Sokak, No:14/8 Kadıköy - ISTANBUL / TURKIYE 34714 Kadıköy - ISTANBUL / TURKEY 34714 e-posta: editor@rumelide.com $\quad$ e-mail: editor@rumelide.com, tel: +90 $5057958124,+902167730616$ phone: +90 505 7958124, +90 2167730616
} 
üzerinde yeniden üretildiği ve yasallaştırıldığı temel bir mihenk taşı olarak da karşımıza çıkmaktaydı (Pérez-Milans, 2017, s. 208-209). ${ }^{25}$

Bu doğrultuda son elli yılda, İngilizcenin toplumun son derece küçük bir kesiminin ki bu kesim çevirmen ve tercümanlardır, bildiği bir dil olmaktan çııı gitgide daha fazla insanın "yüksek iki dillilik seviyesinde hâkim olduğu bir dil haline gelmesi Hong Kong Hükümeti’nin hedefleri” (O'Halloran, 2000, s. 146) arasında önemli bir yere sahiptir. Hong Kong Eğitim Bürosu resmi internet sitesinde de bu hedefi, öğrencilerin: "Daha iyi eğitim ve hayat için iki dil okuma yazma [ve] üç dil konuşma üzerine uzmanlaşma” (HKSAR Education Bureau, 2017, para.4) sağlamasını destekleme olarak belirtmektedir. $\mathrm{Bu}$ doğrultuda 2021 yllında Eğitim Sekreteri Kevin Yeung Yun-hung, "Dil Eğitimi ve Araştırma Komitesi”nin 25. Yllı konferansında hükümetin bu doğrultuda emin adımlar ile ilerlediğini ifade ederken bu dil politikasının: "Çince ve İngilizceye olan iyi bir hâkimiyetin kişilerin yalnızca entelektüel gelişimini, akademik başarılarını değil aynı zamanda kariyer olasılıklarını da kolaylaştırdığını” (Yunhung, 2021, para.6) belirtmiştir.

1984 ylında imzalanan anlaşma gereğince, 1997 yllındaki devri ardından bölgenin ana kıta ile olan kültürel, dilsel, politik ve sosyoekonomik farklılıklarını dengelemeyi amaçlayan "bir ülke, iki sistem" (Pérez-Milans, 2017, s. 5) prensibi doğrultusunda, Hong Kong özerk bir bölge olarak Çin hükümetine bağlanır. 1997 sonrasında bu prensip "bir ülke, iki sistem, üç dil” (Evans, 2013, s. 306) olarak değişmeye başlar. ${ }^{26} \mathrm{Bu}$ politika değişikliğinin yansımaları Kantoncanın "yüksek" dil alanlarında (O'Halloran, 2000, s. 147) kullanımının hızlanması olarak kendini hissettirir. Özellikle ÇHC hükümetinin 8o’lerden sonra yürüttüğü dışa açılımcı politikalar, 2001 yılında Dünya Ticaret Örgütüne üye olması ve dış ticarette yaşanan büyümenin hız kazanması gibi sebepler nedeniyle Hong Kong, ÇHC’nin dışa açılan kapılarından önemli bir tanesi haline gelmiştir. Bu durum ise bölgenin yabancı dil, yani çok iyi derecede İngilizce ve Mandarin Çince, bilen işgücüne olan ihtiyacının tahmin edilemez derecede artmasında önemli rol oynamıştır.

Bu ihtiyacı karşılayabilmek adına Hong Kong Özel İdari Bölge yönetimi: İngilizcenin yanı sıra "ana kıta Çin Halk Cumhuriyeti topraklarında, ulusal dil olarak yarım asırdan fazla bir süredir kabul görmüş olan Mandarin Çincenin, eğitim sisteminde yerini alması gerektiğine karar kılmış” (Evans, 2013, s. 306); Mandarin Çince derslerini okullarda zorunlu bir hale getirerek bölgeyi çok dilli bir yapıya kavuşturmuş; "iki dilli okuryazarlık ve üç dillilik" (Li D., 2017, s. 73) politikasının ilk adımları da böylece atılmıştır.

O'Halloran, HKÖİB hükümetinin 2000 yll öncesindeki dil politikasına dair şunları anlatır:

İngilizce ve Kantoncanın resmi statüsü, devir sonrasında hazırlanan Temel Kanun'nun 9. Maddesine göre garanti altına alınmıştır. İngilizce sivil memur hizmetleri, iş dünyasının üst kademeleri ve profesyonel sektörlerde ve hatta yükseköğrenimde iletişim aracı olarak yerleşik biçimde kullanılmaya başlanmıştır. Buna rağmen tekrar Çin himayesine geçtikten sonra hükümet, sivil hizmetlerin Çinceİngilizce iki dilli okur-yazar ve Çince-İngilizce-Kantonca üç dil [konuşur] olmasını amaçlayan bir dil politikasına biçim vermiştir (O'Halloran, 2000, s. 147).

1997 yllındaki devir işleminin hemen ardından HKÖİB eğitim alanında uygulamaya koyacağ politikayı yayımladığı "Kılavuz (Guidance)" içinde açılar (Education Commission , 2005, s. 6). Bölgede bulunan pek çok orta ve lise düzeyindeki okulun (7-12. sınıf) eğitim dillerini Kantoncaya çevirmesi, yani bu okullarda anadille eğitim verilmesi talebinde bulunur. Hong Kong Eğitim Bürosu, gelecek eğitim

25 Burada kastedilen konuşma dili olarak "Kantonca" ve yazı dilinde ise "Klasik Çincedir".

26 Bir ülke, iki sistem, üç dil ve ulaşılmak istenen hedefler hakkında daha geniş bilgi için bk. Wright, S., \& Kelly-Holmes, H. (Eds.). (1997). One country, two systems, three languages: a survey of changing language use in Hong Kong (Vol. 3, No. 2). Bristol: Multilingual Matters.

RumeliDE Dil ve Edebiyat Araştırmaları Dergisi Osmanağa Mahallesi, Mürver Çiçeği Sokak, No:14/8 Kadıköy - ÍSTANBUL / TÜRKIYE 34714 e-posta: editor@rumelide.com tel: +90 505 7958124, +90 2167730616
Address

RumeliDE Journal of Language and Literature Studies

Osmanağa Mahallesi, Mürver Çiçeği Sokak, No:14/8

Kadıköy - ISTANBUL / TURKEY 34714

e-mail: editor@rumelide.com,

phone: +90 505 7958124, +90 2167730616 
döneminden (1998-1999) itibaren uygulanmak üzere, önceden belirlenen İngilizce standartlarını yakalayamayan hocalara ya da öğrencilere sahip okulların (yapılacak olan sınavlarda yeterli başarı gösteremeyen), EDİ ile kaliteli bir eğitim standardını tutturamayacaklarını ve bu yüzden eğitim dillerini Kantoncaya çevirmeleri gerektiğini söyler. İngilizceyi eğitim dili olarak kullanmak isteyen okulların ise belli başlı üç kriteri sağlamaları gerekmektedir: 1) Okuldaki öğrencilerin en az \%85’inin İngilizce ile öğrenmede büyük bir sorun yaşamadı̆̆ının, 1995-1998 arası okullarda yapılan "Eğitim Dili Gruplandırma Değerlendirmesi” sonuçlarına göre ispatlanmış olması; 2) Öğretmenlerinin okul müdürü tarafından yahut sertifikalar ile yeterliliğinin ispatlanması; 3) Okulların, öğrencilere hızlı kurslar ve benzeri yardımcı programlar verebilmek için gerekli alt yapıya dair hazırlıkları yapmış olmaları (Education Commission , 2005, s. 7).

Bu dil politikası, bölgede bulunan yaklaşık üç yüz okulun iki yüz tanesini, eğitim dili olarak Kantonca kullanmaya başlamak zorunda bırakır. Ama çocuklarının gittiği okulların EDİ statüsünden EDÇ’ye çevrilmesi, velileri rahatsı etmiş ve onların direnişi ile karşılaşmıştır. Ana dilde eğitim, çocukların konuları daha hızlı ve iyi kavramalarına yol açtığından, akademik olarak başarılı olmalarını sağlasa bile: Hong Kong üniversitelerinin çoğunda İngilizce eğitim (EDİ) veriliyor olması; iş piyasasında başarı sağlamak için İngilizcenin hala olmazsa olmazlardan biri olarak düşünülüyor olması (Education Commission , 2005, s. 13); bu iki duruma rağmen orta ve lise düzeyindeki okulların çoğunun EDÇ’ye zorunlu olarak dönüştürülmüş olması gibi sebepler, velilerin çocukları için hayal ettikleri gelecek tablosunun temelden sarsılmasına yol açmıştır (Evans, 2002, s. 97-98). Bu durum ve EDÇ okulların ikinci sınıf okullar olarak düşünülmesi, en iyi öğrencilerin elit EDİ okullarda eğitim görenler oldukları algısını güçlendirmiş (Chan, 2014, s. 461) ve bu yüzden, veliler tarafından toplum içinde çatışma ortamı ve ayrımcllığa yol açtığı düşünülen bir unsur haline gelmiştir (Choi, 2003, s.675-676, 678; Evans, 2002, s. 98). 1997-98 yılları arasında, sadece yüz yirmi dört okulun EDİ kullanmasına izin veren (O'Halloran, 2000, s. 151) hükümetin, bu yeni eğitim dili politikasıyla yarattığı tartışma ortamı uzun süre devam etmiş, hatta 2009 yllında var olan hoşnutsuzluğun giderilmesini amacıyla ortaya atılan "ince ayar politikasına (fine-tuning policy)"27 kadar süregelmiştir. 2005 yılında Hong Kong Eğitim Komisyonu tarafından hazırlanan, "Orta Okullarda Eğitim Dili Raporu” içinde bu politikanın amacı: "ana dilde öğretimi korumak ve İngilizce yeterliliğini geliştirmek” (Education Commission , 2005, s. 2) olarak açılanmış, politikanın yetkinliği ise hükümet ve üniversiteler tarafından yapılan araştırma sonuçlarından elde edilen veriler sonrasında şu maddeler altında açıklanmıştır:

1) Öğretme ve öğrenme aşamasında, öğretmenlerin ana dilde eğitim ile beraber daha derin ve efektif eğitim verdikleri; öğrencilerin ise sınıflarda daha aktif oldukları ve dersleri daha kolay anladıkları; analitik düşünme ve soyut düşünme kabiliyetlerinin daha kolay geliştiği;

2) Kişisel gelişim anlamında, öğrencilerin başarı tatminlerindeki yükselişin, kendine güven duygusuna olumlu yönde etki ettiği, motivasyonlarını arttırdığı;

3) Akademik performans anlamında, öğrencilerin fen ve sosyal bilimler üzerine başarı oranlarının yükseldiği, ancak İngilizceye olan ilgi ve motivasyonlarının düştüğü;

4) Akademik anlamda, EDİ ile öğrenim görmüş öğrencilerin yükseköğrenim giriş sinavlarında daha yüksek puan aldığı ve daha başarılı olduğu; ancak EDÇ öğrencilerin başarı oranlarının da artış gösterdiği; bu doğrultuda, üniversite kabullerinin orta ve lise düzeyinde görülen eğitim başarısına göre

27 Politika hakkında daha geniş bilgi için lütfen bkz. Chan, J. Y. (2014). Fine-tuning language policy in Hong Kong education: stakeholders' perceptions, practices and challenges. Language and Education, 28(5), s. 459-476. Adres | Address

RumeliDE Dil ve Edebiyat Araş̧trmaları Dergisi $\quad$ RumeliDE Journal of Language and Literature Studies Osmanağa Mahallesi, Mürver Cicceği Sokkak, No:14/8 Osmanağa Mahallesi, Mürver Çiçeği Sokak, No:14/8 Kadıköy - İSTANBUL / TÜRKIYE 34714 Kadıköy - ISTANBUL / TURKEY 34714 e-posta: editor@rumelide.com e-mail: editor@rumelide.com, tel: +90 $5057958124,+90216773$ o 616 phone: +90 505 7958124, +90 2167730616 
yapıldığı ve EDÇ okullardan gelen öğrencilerin bu anlamda üniversiteye daha kolay girdikleri saptanmıştır (Education Commission , 2005, s. 8-13).

Yukarda bahsi geçen resmi araştırmaların aksine bir sonuca 2008 yılında ulaşan Tsang'ın araştırmasına göre ise; "EDİ okulu mezunları arasından üniversiteye girenlerin sayısının, EDÇ okulu mezunlarına oranla çok daha fazla olduğu” (Tsang, 2008) saptanmıştır. Bu anlamda iki çalışmanın birbiri ile olan tutarsızlı̆̆ ilgi çekicidir. Bunun nedeni, Tsang'n daha küçük bir grup ile çalışmayı yapmış olmasında; yahut hükümetin, uyguladığı politikanın pozitif yanlarını öne çıarmak istediği düşüncesinde yatabilir.

Kısaca özetlemek gerekirse, eğitim dili politikaları bağlamında, Hong Kong örneği geçmişten günümüze üç döneme ayrılabilir: 1) Koloni hükümetinin laissez-faire politikası (serbest politika) ki bunda her okul kendi eğitim dilini seçme hakkına sahiptir (1946-97 yılları arası dönem); 2) Zorunlu ana dilde eğitim politikası ki bu 1998 sonrasında yürürlüğe konulan ve yukarıda bahsedilen politikadır (1998-2009 yılları arası dönem); 3) 2009 yılında hazırlanan "ince ayar" politikası sonrasındaki dönem (Poon A. , 2013, s. 46) ki okulların hangi dersleri İngilizce vermek istediklerine "bazı koşullar dâhilinde" (Chan, 2014, s. 461) kendilerinin karar verebileceğini ifade eden bu politika değişikliği, günümüze kadar uzanmaktadır (2010-...). İnce ayar politikası ile EDİ ve EDÇ kullanan okulların arasında oluşan ayrışma ortadan kaldırılmaya çalışılmış, 2010 yılı sonlarına doğru bu politikaya uygun ders programlarının okulların ve öğretmenlerin yetkinliklerine göre uygulanmaya başlanmasına karar verilmiştir (HKSAR Education Bureau, 2010, s. 1). Bu teşebbüsün amacı, EDİ ve EDÇ olan okulların üzerine yapışmış yaftaları ortadan kaldırmak, her okulun kendi eğitim dili seçimlerini öğrenci ve öğretmenlerin yeterliliklerine göre karar vermesine olanak sağlayacak esnekliği sağlamaktır. Ana dilde eğitim politikasına yapılan bu "ince ayar"ın kapsamı Eğitim Bürosu tarafından ana dilde eğitim için belirlenen temel kriterlere ek olarak şu maddelerle açıklanmıştır:

1) İngilizce derslerine ek olarak verilen genişletilmiş öğrenme aktivitelerinin saati arttırılacaktır.

2) Okullar, öğrenci motivasyonunu arttırmak ve öğrencilerin lisede EDİ olan okullara geçiş yapabileceklerini göz önünde bulundurarak, dil ile alakalı olmayan dersler arasından, iki dersin İngilizce öğretilmesine karar verebilecektir.

3) \%85’lik öğrenci yeterliliğini (İngilizce ile öğretileni anlama becerisi; iyi ve yüksek seviye İngilizce) sağlayan okullar, kendi eğitim dili düzenlemelerini yapabilecek yetkiye sahip olacaktır.

4)Yukarda belirtilen çerçevede okulların EDİ ve EDÇ gibi etiketleri bulunmayacak ve böylelikle okullardaki uygulamalar da çeşitlilik kazanacaktır (HKSAR Education Bureau, 2009, s. 2-4).

Görünen odur ki 1997 yllında devreye sokulan ana dilde eğitim politikasının öğrenci velilerinde yarattığı rahatsızlık, 2009'da yürürlüğe giren ince-ayar politikası ile beraber giderilmeye çalışılmıştır. Veli ve öğrencilerde bu yeni politikanın bir nebze olsun rahatlama yaratmasının temel nedeni olarak; okulların, bu dönemden sonra EDÇ ya da EDİ okullar olarak ayrıştırılmalarından ziyade, hangi ders ve konuların EDÇ ya da EDİ kullanılarak öğretildiği yönünde sınıflandırılmaya başlanmış olmasında yatmaktadır. Bu politika ile EDÇ eğitim almakta olan öğrencilerin İngilizce ile gördükleri ders miktarının \%25 fazlalaştırılması (Lai, 2013, s. 313) ve bu doğrultuda EDİ-EDÇ okullar arasında yaşanan sosyal ayrışmanın ortadan kaldırılması amaçlanmıştır (Li D. , 2017, s. 197). Bu politika öğrencilerin "öğrenme motivasyonunu ve öz-değerlerini yükseltmiş” (Poon A. , 2013, s. 46), politika uygulanmaya başlandıktan

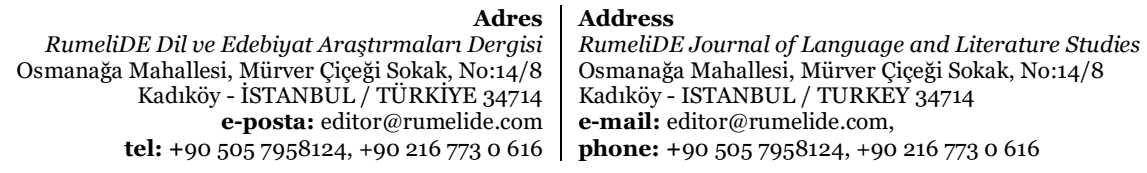


sonra öğrencilerin özellikle İngilizce eğitim veren üniversitelere girdikten sonra yaşadığı adaptasyon sorununda da azalma kaydedilmiştir. ${ }^{28}$

İnce ayar politikasına, öğretmenler ve öğrencilerin bakışı ile değişken eğitim dilinin öğretim, öğrenme ve İngilizce yetkinlikleri üzerine etkisine dair, Poon ve Lau'nun 2016 yılında yayımladıkları, 2012 yllında EDİ dersler ve bazı yarı-EDİ derslerin verildiği iki orta kalite devlet destekli okulun öğrencileri üzerinde yapılan araştırma sonuçlarına göre: öğretmenler, EDÇ'den EDİ'ye geçilen derslerde, kavram ve terim tek tek açıklanmak zorunda kalındığını, bu nedenle ders hazırlarken ve anlatırken daha fazla zamana ihtiyaç duyulduğunu, ancak belli bir süre sonra İngilizce verilen sayısal derslere (dil kullanım gereksinimi düşük olan matematik, fen bilimleri gibi) öğrencilerin adapte olduklarını, tarih, coğrafya gibi dil kullanımı yüksek derslerde ise sorun yaşadıklarını ve öğrencilerin sınıftaki aktifliklerinin zedelendiğini belirtmişlerdir. Araştırma sonucunda, hem İngilizceyi hem de içerik temelli konuları anlamaya çalışan öğrencilerin zorlandıkları, öğretmenlerin ise bazı konuları öğrencilerin anlayabilmesi için daha yüzeysel anlatmak zorunda kaldıkları tespit edilmiştir. Öğrenciler, öğrenme sürelerinin uzamasına rağmen zor olsa da bazı dersleri İngilizce almaktan hoşlandıklarını ifade etmiş, ancak öğretmenlerin yarı İngilizce yarı Çince ders işlemelerinden, yani karma kodlar kullanmalarından yana rahatsız olduklarını ve bu durumun anlamayı zorlaştırdığını ifade etmişlerdir (Poon \& Lau, 2016, s. 139144).

Yukarıda bahsi geçen, Eğitim Komisyonu, Poon ve Lau ile Tsang'ın yürüttüğü araştırmalara, lise sonrası yükseköğrenim ve/veya kurs gören Çinli öğrencilere dair resmi istatistik verileri eklenerek basit bir analiz yapılacak olursa şöyle bir sonuca varılabilir:

Hong Kong'da 2001 yılında lise sonrası eğitimine devam eden kesim üzerinde yapılan resmi araştırma verilerine göre: 1991-2001 arası sırasıyla on beş yaş ve üzeri (yabancılar hariç) lise sonrası sertifika kursları ve üniversite gibi yerlerde eğitimine devam edenlerin, nüfusa oranları sırasıly: 1991 yılı itibariyle \%23,11; 1996 yll itibariyle \%21,26; ve 2001 yll itibariyle \%25,83 olarak görünmektedir (Census an Statistics Department, 2002, s. 42). En son 2016 yılında yapılan ve 2017 yllında açıklanan resmi sayım verilerine göre ise: 2006-2016 yılları arası on beş yaş ve üzeri (yabancılar hariç) lise sonrası sertifika, ön lisans, lisans ve üzeri eğitim düzeyine sahip olan nüfusun toplam nüfusa oranı: 2006 yllında \%48,42; 2011 yllında \%49,99; 2016 yllında ise \%52,72 olarak tespit edilmiştir (Census and Statistics Department, 2017b, s. 48). Bu anlamda, Tsang'n (2008) araştırmasının aksine, 1997 sonrası ana dilde eğitim politikasının yükseköğrenim gören kişi sayısında ilk dokuz yl içerisinde hızlı bir artışa sebep olduğu, bu hızlı artışın ise 2006 ve aslen 2009 "ince ayar" politikasından sonra, daha yatay seyirli bir ivmeye dönüştüğü; Poon ve Lau’nun araştırmasına göre, öğrencilerin İngilizce dersleri anlamada sorun yaşadığı ve bu sorunun lise sonrası eğitime yansımaları olduğu düşünülebilir. Bu anlamda, ivmedeki düşüşün devam etmekte olması, 2010 öğretim yılında uygulamaya konulan ince-ayar politikasının, yükseköğrenim hakkı kazanan ve devam eden öğrenci sayılarında, pozitif yönde büyük bir etki yaratmadığı söylenebilir.

\section{Hong Kong'da kullanılan resmi diller üzerine istatistiksel veriler}

Bölgede konuşulan diller ile alakalı ilk defa 1911 yılında yapılan sayımdan bugüne, hükümet elde edilen verileri düzenleyerek yayımlamaya devam etmektedir. İngilizce ile alakalı ilk verinin toplanmasına ise

$28 \quad$ Burada adaptasyon sorunu ile kastedilen İngilizce'nin sadece yabancı dil dersi olarak müfredatta yer aldığı EDÇ okullardan mezun öğrencilerin, üniversiteye girdikten sonra İngilizce ders görmeye başlamasının yarattığ zorluk ve rahatsızlıktır. Doğal olarak öğrencilerin üniversitedeki başarı ortalamalarını etkileyen bu durum, velilerin de EDÇ okullarına olan negatif yaklaşımının nedenlerindendir. Adres Address

RumeliDE Dil ve Edebiyat Araştırmalarn Dergisi $\quad$ RumeliDE Journal of Language and Literature Studies Osmanağa Mahallesi, Mürver Çiçeği Sokak, No:14/8 Osmanağa Mahallesi, Mürver Çiçeği Sokak, No:14/8 Kadıköy - İSTANBUL / TÜRKIYE 34714 Kadıköy - ISTANBUL / TURKEY 34714 e-posta: editor@rumelide.com tel: +90 $5057958124,+902167730616$

e-mail: editor@rumelide.com,

phone: +90 5057958124 , +90 2167730616 
1931 yllında başlanmıştır. En son 2017 yılında yayımlanan ve 2022 yılında yenisinin yayımlanması beklenen araştırmalarda, sayım yetkilileri sayıma katılan halka yabancı dil okuryazarlığı ile alakalı: 1) Günlük hayatta kullandıkları dili; 2) Konuştukları dil/dillerin neler olduğunu sormuşlardır (BaconShone \& Bolton, 2008, s. 31). Bu soruların cevaplarına dair 1931-2006 arası sonuçlar Şekil 1 de, 20062016 ylları arası sonuçlar ise Tablo 1'de yer almaktadır. Bölgede belirtilen dillerin yanısıra; Hakka, Fukien, Shanghainese, Chiu Chau ve benzeri birden çok diyalekt de kullanılmaktadır. Ancak bu diyalektleri konuşan nüfus nispeten düşük miktarda olduğundan ve diyalektler hükmet tarafindan resmi dil statüsünde kullanılmadığından bu araştırmanın dışında tutulmaları uygun görülmüştür.

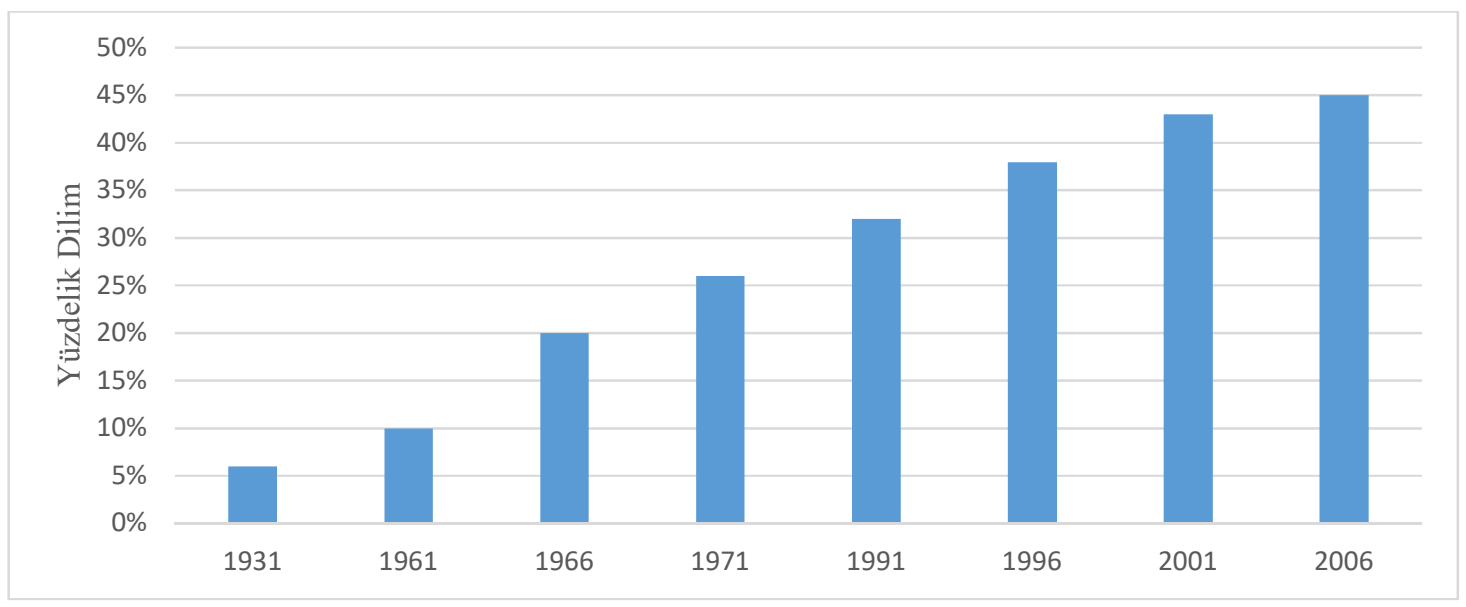

Şekil 1. Hükümet sayım raporlarına göre 1931-2006 arası Hong Kong'da İngilizce bilenlerin nüfusa oranı (Bacon-Shone \& Bolton, 2008, s. 32)

Tablo 1. Resmi Verilere Göre 2006-2016 Arası 5 Yaş ve Üzeri Seçili Dilleri Konuşanların Nüfusa Oranı*

\begin{tabular}{|c|c|c|c|c|c|c|c|c|c|}
\hline \multirow[b]{3}{*}{ Y1l } & \multicolumn{9}{|c|}{ Nüfusa Göre 5 Yaş ve Üzeri Yüzdelik Oranlar } \\
\hline & \multicolumn{3}{|c|}{ Ana Dil } & \multicolumn{3}{|c|}{ Yabancı Dil/Diyalekt } & \multicolumn{3}{|c|}{ Toplam } \\
\hline & 2006 & 2011 & 2016 & 2006 & 2011 & 2016 & 2006 & 2011 & 2016 \\
\hline \multicolumn{10}{|c|}{ Dil/Dialekt } \\
\hline Kantonca & 90,8 & 89,5 & 88,9 & 5,7 & 6,3 & 5,7 & 96,5 & 95,8 & 94,6 \\
\hline İngilizce & 2,8 & 3,5 & 4,3 & 41,9 & 42,6 & 48,9 & 44,7 & 46,1 & 53,2 \\
\hline Mandarin & 0,9 & 1,4 & 1,9 & 39,2 & 46,5 & 46,7 & 40,2 & 47,8 & 48,6 \\
\hline
\end{tabular}

*Hong Kong Nüfus Sayım ve İstatistikleri resmi sitesi üzerinden alınarak düzenlenmiştir (Census and Statistics Department, 2017a).

Yukarıda, Hong Kong hükümeti tarafından rapora dökülmüş olan beşer yıllık verilerin ışığı altında, HKÖİB bölgesinde kullanılan diller arasında İngilizce ve Mandarin Çince ile ilgili şu yorumları yapmak mümkündür:

1) 1931 yllında nüfusun çok küçük bir kısmı İngilizce bildiğini söylemektedir. Daha evvel bahsedildiği üzere bu kesimin çoğu devlet kadrolarında, hukuk, eğitim ya da tercüme faaliyetlerinde aracı konumunda olan elit tabakadan oluşmaktadır;

2) 1961-96 ylları hızla ivmelenen İngilizce bilen nüfus oranı, 1997 yılında yaşanan devir teslimi öncesi \%38'lere kadar ulaşmıştır. Bu da Hong Kong Koloni Hükümeti’nin, İngilizceyi yaygınlaştırma

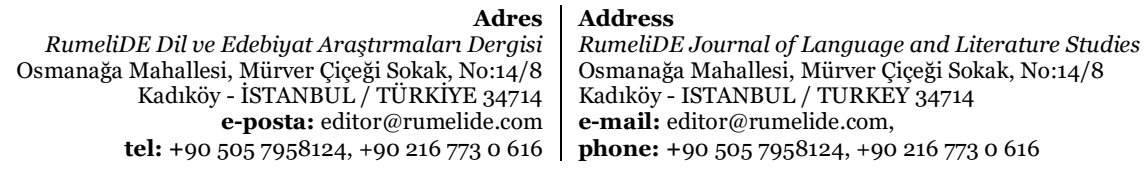


politikasında ne kadar başarılı olduğunun ve ticari bir liman ve finans merkezi görevini üstlenen Hong Kong'da İngilizcenin ne kadar önemli bir değere sahip olduğunun bir göstergesi olarak alınabilir.

3) 1997 yllında HKÖİB hükümetinin uygulamaya koyduğu "ana dilde eğitim" politikasının, İngilizce bilen oranının ivmesinde ciddi bir düşüş yarattığı ve bu anlamda ana dilde eğitim politikası olarak başarı gösterse de bölgenin çok dilli potansiyeline darbe vurduğu düşünülebilir. Her beş ylllı periyot içinde, İngilizce bilen sayısındaki ortalama ivme \%2-3 oranının üzerine çıamamış, bu durum 2016 ylındaki sayıma kadar İngilizce için bu şekilde devam etmiş görünmektedir.

4) 2009 yllında yürürlüğe konan ince-ayar politikasının etkisi 2016 yllında İngilizce bilen oranı ivmesindeki artıştan gözlemlenebilmektedir. Eldeki veriler ışığında incelendiğinde bu yeni politikanın İngilizce öğreniminde yaşanan düşüşü düzelttiğini söylemek yanlış olmaz. Ancak bu politikanın gerçekten de başarılı olup olmadığına dair kesin bir yargıda bulunabilmek adına en azından sonraki beş yıllık periyodun sonunda yayımlanacak olan sayım sonuçlarının da hesaba katılmasının daha net sonuçlar vereceği düşünülmektedir.

5) Yukarıdaki veriler karşılaştırıldığında ana dilde eğitimin aslen yabancı dil edinimini çok yüksek bir oranda etkilemediği de düşünülebilir. Ancak tabii ki bu hususta daha net bir şey söyleyebilmek adına İngilizce konuşanların dildeki yetkinliklerinin de göz önünde bulundurulduğu veriler üzerine araştırmalar yapılması gerekmektedir. Ayrıca elde edilen verilerin kişilerin söylemlerine bağlı olduğu ve gerçeği yansıtmayabileceği de düşünülmesi gereken başka bir husustur.

6) 2001 yllında Çin Hükümetinin Dünya Ticaret Örgütüne üye olması ile hızlanan ticari ortam ve 1997 ylında orta ve lise düzeyinde uygulanmaya konan zorunlu Mandarin derslerinin işe yarayı yaramadığını anlamak için 1993-2003 yılları arasında yapılan araştırmalarda, orta seviye üzerinde Mandarin Çince konuştuğunu söyleyen kişilerin oranlarına da bakılması gerekli görülmektedir. BaconShone ve Bolton'nun araştırmalarına göre; 1993 yılında orta ve üzeri seviyede Mandarin Çince konuşanların oranı \%29'dur (Bacon-Shone \& Bolton, 2008, s. 39). Tablo 1'e göre 2006 yllında bu oran \%40 civarına kadar çıkmıştır. 2011 yılında \%48 civarına kadar çıkan oran 2016 yılında yapılan sayımda \%49 civarında bir orana sahiptir, yani ivme kaybetmesine rağmen her periyotta artmaya devam etmektedir ki zorunlu Mandarin Çince dersleri ile başarı sağlandığı söylenebilir.

\section{Sonuç}

İki dillilik araştırmalarında Hong Kong, pek çok farklı açıdan dikkatle incelenmesi gereken hassas bir bölgedir. Bu araştırmada, 1841 yılında İngiliz sömürgesi olmasından bugüne, Hong Kong'un dilsel yapısı tarihi olayların ışı̆̆ı altında incelenmeye ve aktarılmaya çalışılmıştır. Çalışmamızda ele aldığımız Hong Kong, bugün dil-eğitim politikaları olarak hala kullanılmakta olan; ana dilde eğitimin, İngilizce ile eğitimin ve karma, yani son dönemde kullanılan "ince ayarlı ana dilde eğitimin" doğurduğu sonuçlar açısından, hükümetin yayımladığı veriler doğrultusunda incelenerek, bölgenin çok dilli yapısının gelecekteki durumu öngörülmeye çalışılmıştır. Araştırmada elde edilen bulgular şu şekilde özetlenebilir:

Dil politikasının değişimi ve EDÇ planlaması sonrasında, yükseköğrenim gören Hong Kong’lu sayısının, özellikle 1997'de "ana dilde eğitim" politikasının devreye girmesinden itibaren, bir buçuk kat arttığı, Mandarin Çince konuşabilen Hong Kong'lu sayısının da yine aynı dönemden sonra benzer bir çizgi izlediği tespit edilmiştir. "Ana dilde eğitim” politikasının, üniversiteye giden öğrenci sayılarına etkisi üzerine resmi veriler incelendikten sonra, istenilen başarının yakalandığı düşünülmektedir. 2001

\footnotetext{
Adres | Address

RumeliDE Dil ve Edebiyat Araştırmaları Dergisi $\quad$ RumeliDE Journal of Language and Literature Studies Osmanağa Mahallesi, Mürver Çiçeği Sokak, No:14/8 $\quad$ Osmanağa Mahallesi, Mürver Çiçeği Sokak, No:14/8 Kadıköy - ISTANBUL / TURKIYE 34714 Kadıköy - ISTANBUL / TURKEY 34714 e-posta: editor@rumelide.com e-mail: editor@rumelide.com, tel: +90 505 7958124, +90 2167730616 phone: +90 505 7958124, +90 2167730616
} 
ylında Hong Kong Sayım ve İstatistik Kurumu tarafından 15 yaş ve üzeri lise sonrası eğitimine devam eden öğrenci sayısının nüfusa oranı \%25,83 olarak verilmişken; ana dilde eğitim politikasının yürürlüğe girmesinden tam dokuz sene sonra, yani öğrenci nüfusunun büyük çoğunluğu tümüyle EDÇ ile eğitim görüp ilk mezunlarını verdiği sene olan 2006 yılında yapılan sayım sonuçları, bu oranın \%48,42 ye kadar yükselmiş olduğunu göstermektedir. Bu durum Tsang'ın 2008 yılında yaptığı araştırma sonuçlarını çürütmekte, hükümetin ana dilde eğitim politikası ile eğitim seviyesini yukarı çekmeyi başardığını göstermektedir.

İngilizce seviyelerinde ise ana dilde eğitim politikasına geçildikten sonra düşme gözlenmiş, ince ayar politikasının devreye sokulmasıyla bu düşüşün önüne geçilmeye çalışılmıştır. Bu politikanın İngilizce bilen oranlarında, 2006 yılından itibaren yaklaşık \%2'lik ek bir ivme kazandırdığı söylenebilir. 19662001 yılları arası her beş yılda yaklaşı \%5'lik bir ortalama artışa sahip olan İngilizce bilen sayısı, 1997 ana dilde eğitim politikasının ilk mezun verişinden sonra \%3'lük bir ivme kaybına uğramış, 2010 yllında ince ayar politikasının devreye girmesinden sonra ise bu oran tekrar yükselerek \%4 bandına çıkmıştır (Şekil.1; Tablo.1). Bu verilerden yola çıkılarak hükümetin devreye soktuğu ince ayar politikası ile hedeflenen başarıyı yakalamakta olduğu söylenebilir.

1997 sonrası zorunlu ders olarak müfredata giren Mandarin Çincenin, 1993 (Bacon-Shone \& Bolton, 2008) ile 2006 (Tablo.1) yılları arası on üç yllık dönemde ortalama ivmesi \%11, her beş yıllık dönemde ise \%4,3 civarındadır. Bu durum, Mandarin Çince bilen sayllarının bölgede, 1997 öncesi ve ince ayar politikası sonrası İngilizce bilen öğrenci artış ivmeleri ile neredeyse aynı seviyede bir yükselme içinde olduğunu gösterir. Bu anlamda, tek ders üzerinden işlenen Mandarin Çincenin, İngilizceye oranla daha kolay ve hızlı öğrenildiği sonucuna varılabilir.

Bölgede varlığını sürdüren çok dilli yapının bir tür işlevsel çok dillilik olduğu, yani dillerin işlevlerine göre konumlandırıldığı bir yapının varlığı, saptanmıştır. Günümüzde bu konumlar, hükümetin resmi politika değişimi sonrası daha birbiri içine geçmiş görünse de hala İngilizcenin resmi dil olma statüsünü kaybetmemiş olduğu, Kantoncanın ise yavaş da olsa yükseldiği görülmektedir. Bu görev ve işlev farklılaşmasında: halkın sosyal hayatta Kantonca; iş hayatına bakıldığında hükümet, hukuk, eğitim gibi sektörlerde genel olarak İngilizce-Kantonca kullandığı; Mandarin Çincenin ise iş hayatının ticari bölümüne ve ana kıta ile olan görüşmelere ayrılmış olduğu, hala Hong Kong'da kullanılan her dilin kendine has bir kullanım yeri bulunduğu, yani kısacası aslında diglosik yapıdan iki dilli bir yapıya belli konularda geçilmiş olsa da henüz tam anlamıyla çok dilli bir yapıya geçilmediği ifade edilebilir.

Bu çerçevede, "tek ülke, iki sistem, üç dil” bakışı üzerinden oluşturulmaya çalışılan, "iki dil okuryazar, üç dil konuşur” hedefini karşlamaya uygun, hem öğrencilerin İngilizce seviyelerini yükseltme hem de ana dilde eğitimi destekleme isteğine cevap üreten en dengeli politikanın, ana dilde eğitime yapılan "ince ayar" politikası olduğu söylenebilir. Çin hükümetinin gelecek yıllarda ticari anlamda güç kazanmasının, Hong Kong'un dil evrenine etkisinin de büyük olacağı düşünülecek olursa, Dünya'da genel geçer dil (lingua franca) olarak kullanılan İngilizcenin, bölgedeki önemini koruyacağı; Mandarin Çincenin ise iş hayatının vazgeçilmez bir parçası olacağı iddiasında bulunulabilir. Tarihi bir perspektiften bakıldığında iki dilli olan bölgenin, günümüzde artık "resmi” olarak çok dilli bir yapıya geçme çabasında olduğu aşikârdır. Gelecekte ise uygulanan politikaların devamı halinde, Hong Kong'un hızla normal üç dilli bir yapıya kavuşacağını söylemek yanlış olmayacaktır.

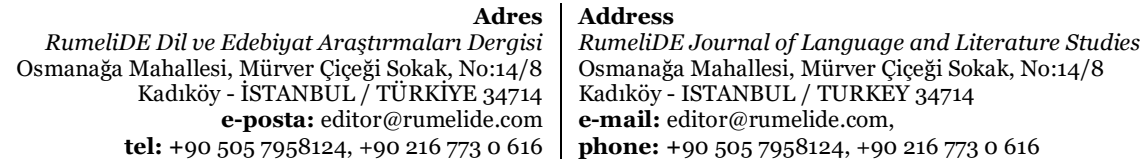

RumeliDE Dil ve Edebiyat Araştırmaları Dergisi tel: +90 $5057958124,+902167730616$ 


\section{Kaynakça}

Appel, R., \& Muysken, P. (1987). Language contact and bilingualism. London: Edward Arnold.

Bacon-Shone, J. ve Bolton, K. (2008). Bilingualism and multilingualism in the HKSAR: Language Surveys and Hong Kong's Changing Linguistic Profile. Language and Society in Hong Kong, s. 2551.

Beziers, M. ve Van Overbeke, M. (1968). Le bilinguisme. Essai de définition et guide bibliographique. Louvain: Librairie universitaire.

Bloomfield, L. (1935). Language (revised edition). London: George Allen \& Unwin Ltd.

Census and Statistics Department. (2002). 2001 Population by-census: summary results. Hong Kong Government. Population By-census Office.

https://www.censtatd.gov.hk/en/data/stat_report/product/B1120018/att/B11200182001XXX XB0100.pdf adresinden alındı

Census and Statistics Department. (2017a). 2016 Population by-census. HKSAR Population by-census: https://www.bycensus2016.gov.hk/en/bc-mt.html?search=A111 adresinden alındl

Census and Statistics Department. (2017b). 2016 Population by-census: summary results. Hong Kong Government. Population By-census Office.

https://www.censtatd.gov.hk/en/data/stat_report/product/B1120094/att/B11200942016XXX XB0100.pdf adresinden alındl

Chan, J. Y. (2014). Fine-tuning language policy in Hong Kong education: stakeholders' perceptions, practices and challenges. Language and Education, 28(5), s. 459-476.

ÇHC. (2021). The Constitution of the People's Republic of China. The Basic Law of Hong Kong Special Administrative Region of the People's Republic of China. Çin Halk Cumhuriyeti. https://www.basiclaw.gov.hk/filemanager/content/en/files/basiclawtext/basiclaw_full_text.pd f adresinden alındı

Choi, P. K. (2003). The best students will learn English': Ultra-utilitarianism and linguistic imperialism in education in post-1997 Hong Kong. J. Education Policy, 18(6), 673-694.

Education Commission. (2005). Report on review of medium of instruction for secondary schools and secondary places allocation. Hong Kong: Hong Kong SAR Education Commission.

Evans, S. (2002). The medium of instruction in Hong Kong: Policy and practice in the new English and Chinese streams. Research Papers in Education, 17(1), s. 97-120.

Evans, S. (2013). The long march to biliteracy and trilingualism: Language policy in Hong Kong education since the handover. Annual Review of Applied Linguistics, 33, s. 302-324.

Flowerdew, J. ve Miller, L. (1998). English in Hong Kong and the reversion to Chinese sovereignty. Perspectives: Working Papers of the English Department, City University of Hong Kong, s.46-89.

HKSAR Education Bureau. (2009). Fine-tuning the medium of instruction for secondary schools (Education Bureau Circular No. 6/2009). Hong Kong: Government Printer.

HKSAR Education Bureau. (2017). Seven learning goals of secondary education. Education Bureau: https://www.edb.gov.hk/en/curriculum-development/7-learning-goals/secondary/index.html adresinden alındı

Lai, M. L. (2013). In the period of change-impacts of language education policies on Hong Kong students' learning motivation and achievement. Conference of International Journal of Arts \& Sciences, 6(3), s. 311-322.

Li, D. (2017). Towards 'biliteracy and trilingualism'in Hong Kong (SAR): Problems, dilemmas, and stakeholders' views. Multilingual Hong Kong: Languages, Literacies and Identities içinde (s. 179202). Cham: Springer.

Li, S. M. (1990). The Sino-British joint declaration, 1997, and the land market of Hong Kong. Review of Urban \& Regional Development Studies, 2(1), s. 84-101.

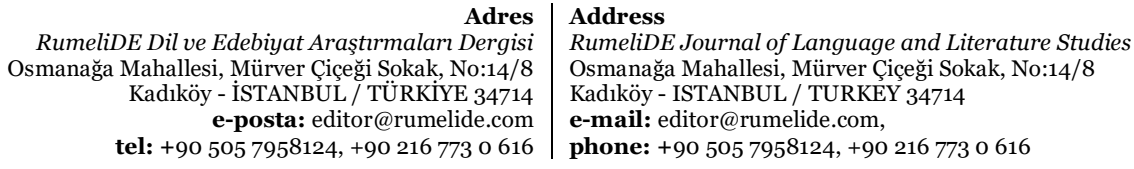


Lin, A., ve Man, E. Y. (2009). Bilingual education: Southeast Asian perspectives. Hong Kong: Hong Kong University Press.

Mackey, W. (1962). The description of bilingualism. Canadian Journal of Linguistics/Revue Canadienne De Linguistique, 7(2), 51-85.

Macnamara, J. (1967). The bilingual's linguistic performance-a psychological overview. Journal of social issues, 23(2), 58-77.

O'Halloran, S. (2000). English medium secondary schools: Privileged orphans in the SAR. Intercultural Communication Studies X, 145-158.

Pennington, M. C. ve Balla, J. (1998). Our future English teachers: Language use among graduate and undergraduate TESL students in Hong Kong. Language in Hong Kong at century's end (Vol. 1) içinde (s. 243-262). Hong Kong: Hong Kong University Press.

Pérez-Milans, M. (2017). Bilingual education in Hong Kong. Encyclopedia of language and education: Bilingual and multilingual education (3. baskı) içinde ( s. 207-218). Cham: Springer International Publishing.

Poon, A. Y. (2010). Language use, and language policy and planning in Hong Kong. Current issues in language planning, 11(1), s. 1-66.

Poon, A. Y. (2013). Will the new fine-tuning medium-of-instruction policy alleviate the threats of dominance of English-medium instruction in Hong Kong? 14(1), 34-51.

The Government of the People's Republic of China and The Government of the United Kingdom of Great Britain and Northern Ireland. (1984). Joint Declaration of the Government of the United Kingdom of Great Britain and Northern Ireland and the Government of the People's Republic of China on the Question of Hong Kong. USC US China Institude: https://china.usc.edu/jointdeclaration-government-united-kingdom-great-britain-and-northern-ireland-and-government adresinden alındı

Tsang, W. K. (2008, 03 14). The effect of medium-of-instruction policy on education advancement. CUHK Faculty of Education Releases. 05 26, 2019 tarihinde http://www.cuhk.edu.hk/cpr/pressrelease/o80314e.htm adresinden alındı

Wang, L. ve Kirkpatrick, A. (2015). Trilingual education in Hong Kong primary schools: an overview. Multilingual Education, 5(1), 1-26.

Yip, D. Y., Tsang, W. K., \& Cheung, S. P. (2003). Evaluation of the effects of medium of instruction on the science learning of Hong Kong secondary students: Performance on the science achievement test. Bilingual Research Journal, 27(2), 295-331.

Yun-hung, M. K. (2021). Opening Remarks at the 25th Anniversary Conference of SCOLAR. Education Bureau: https://www.edb.gov.hk/en/about-edb/press/speeches/sed/20210625181602.html adresinden alınd

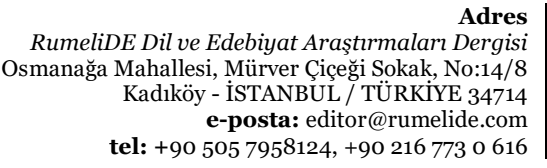

dres

isi

RumeliDE Journal of Language and Literature Studies

Osmanağa Mahallesi, Mürver Çiçeği Sokak, No:14/8

Kadıköy - ISTANBUL / TURKEY 34714

e-mail: editor@rumelide.com,

phone: +90 505 7958124, +90 2167730616 